
\title{
28 Research Suare \\ Lung Cancer That Extended to the Left Atrium Through the Pulmonary Vein: A Case Report
}

\section{Xin Xu}

Lanzhou University Second Hospital https://orcid.org/0000-0002-1069-2149

\section{Ping Xu}

Lanzhou University Second Hospital

\section{Ting Ting Wu}

Lanzhou University Second Hospital

Guo Dong Shang ( $\nabla$ glxyys2010@163.com )

Lanzhou University Second Hospital

\section{Case report}

Keywords: transthoracic echocardiography, Lung cancer, Left atrial, pulmonary vein

Posted Date: April 19th, 2021

DOI: https://doi.org/10.21203/rs.3.rs-413425/v1

License: (9) This work is licensed under a Creative Commons Attribution 4.0 International License. Read Full License 


\section{Abstract}

Background: Metastatic cardiac tumors have been reported in up to $25 \%$ of patients with lung cancer, but detection of cardiac involvement via pulmonary veins is neither uncommon nor easy in the routine work.

Case presentation: A 68-year-old woman with primary lung cancer was admitted to the hospital with pain in her left leg for 6 months and hemoptysis for one week. TTE detected that a hyperechoic mass in the left atrium which was come from the left inferior pulmonary vein. The result was confirmed by computed tomography.

Conclusions: Multimodality imaging should be advocated in the evaluation of cardiac masses especially for patient who has primary tumors.

\section{Full Text}

This preprint is available for download as a PDF.

\section{Figures}

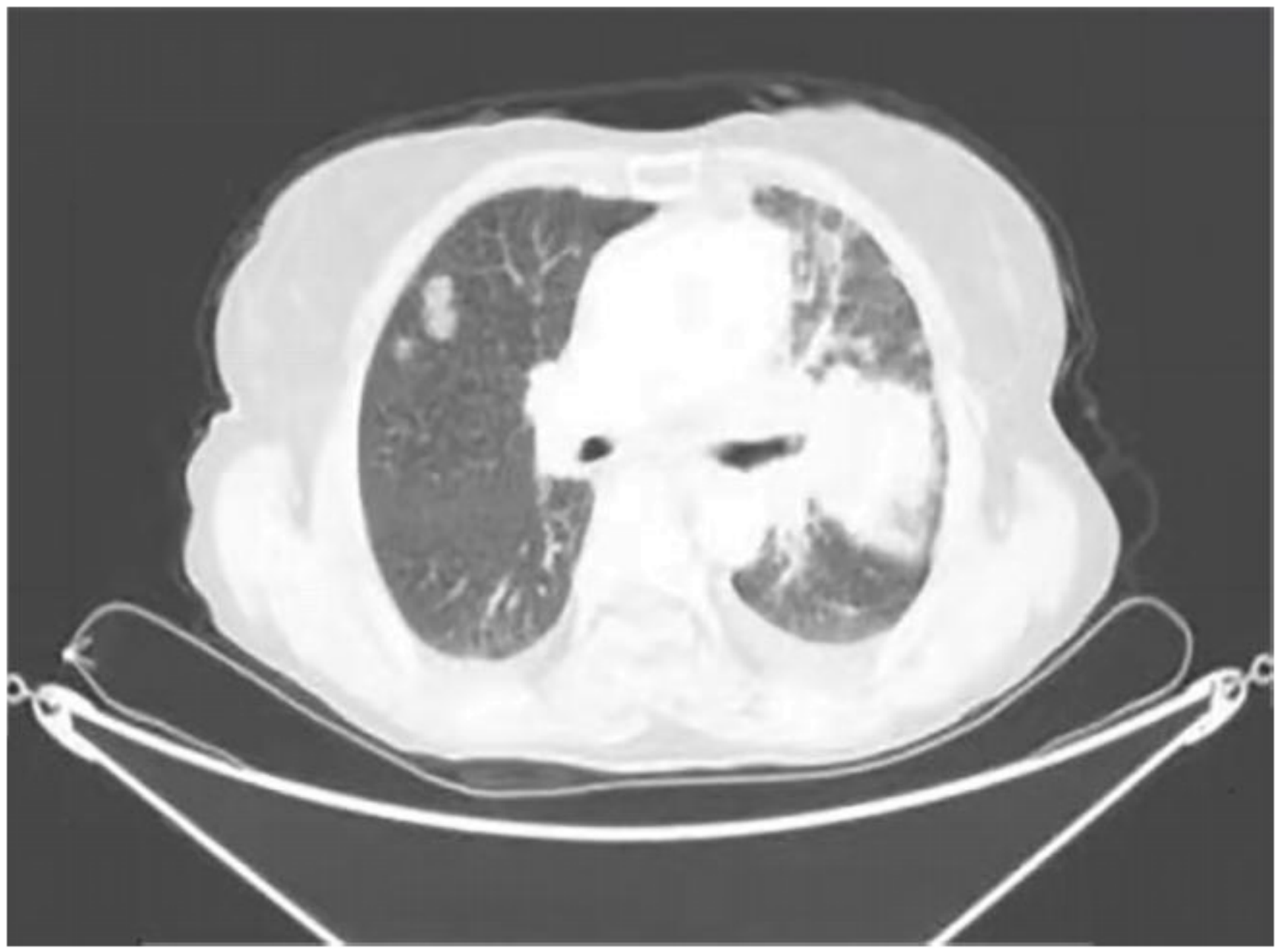


Figure 1

CT scan: Left central lung cancer with right lung metastases

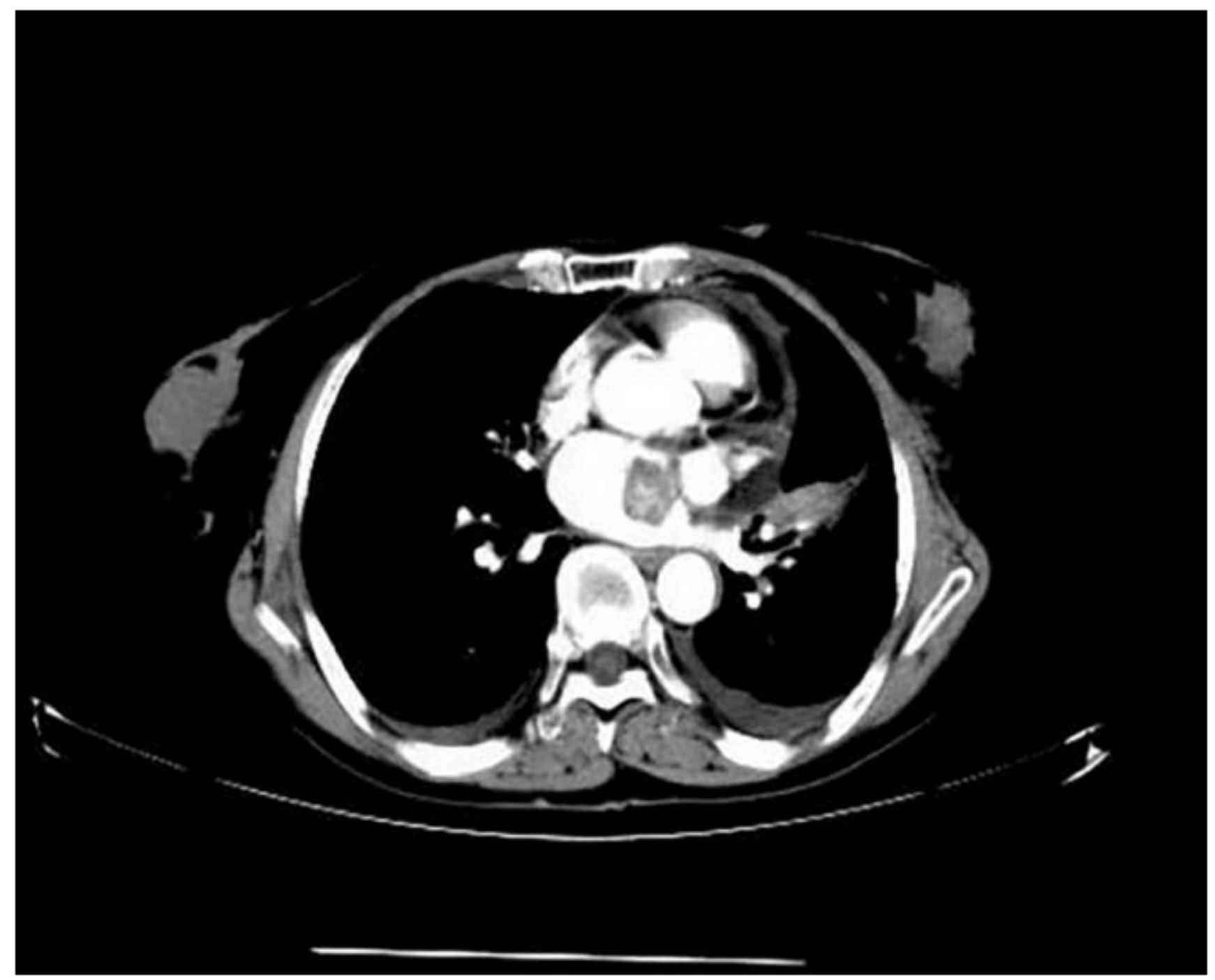

Figure 2

CT invasion of the left pulmonary vein and tumor thrombus in the LA 


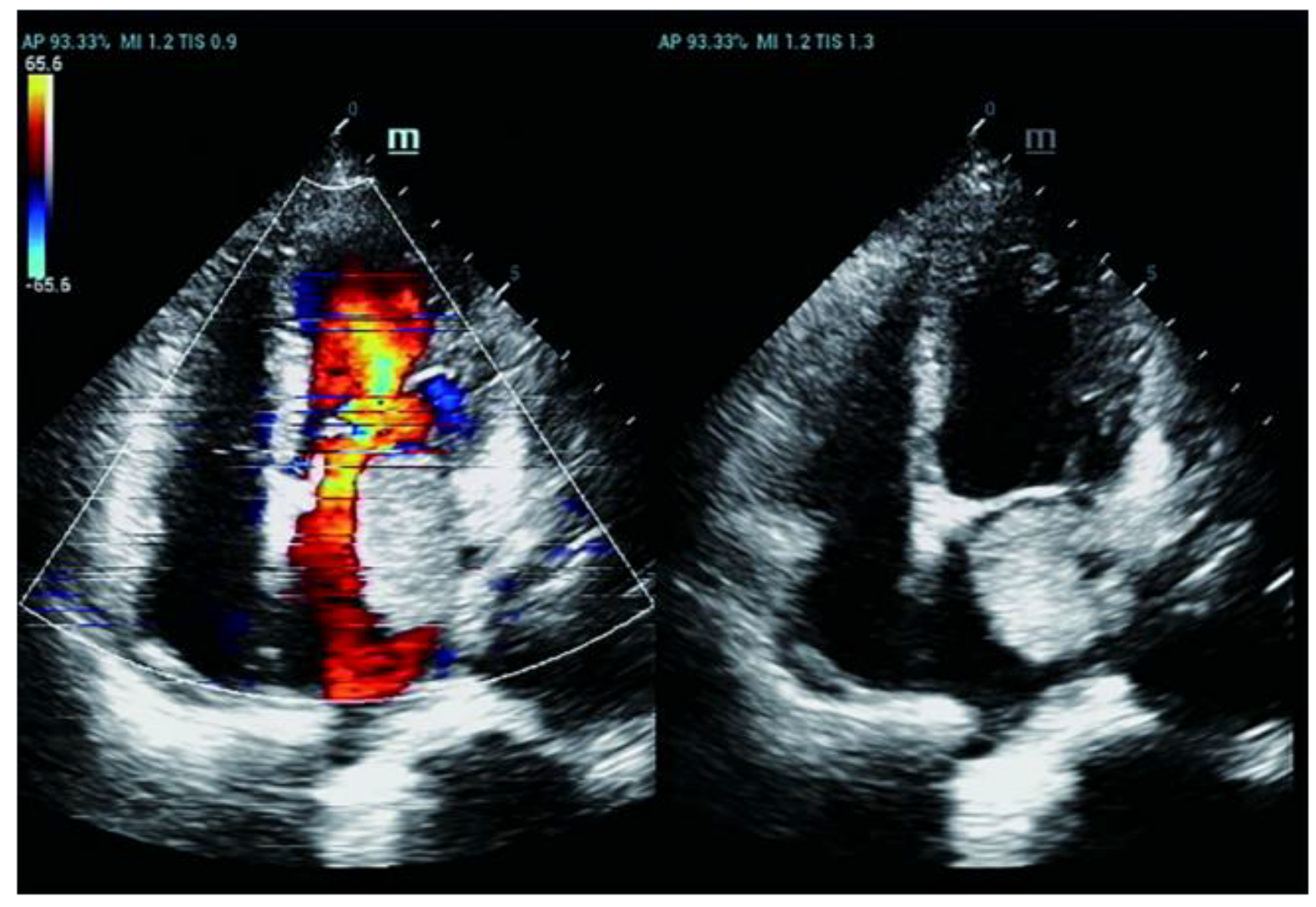

Figure 3

B-mode: hyperechoic mass in the left atrium, the boundary was clear and the base was broad, the internal echo was uniform. Colour Dopper mode: the mass obstructed the entrance of the left pulmonary vein. 